
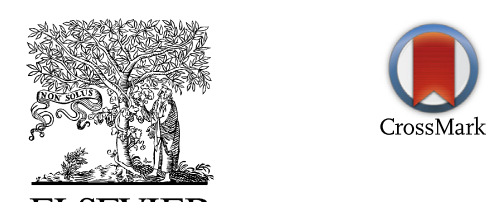

\title{
Indole-3-acetic acid in plant-pathogen interactions: a key molecule for in planta bacterial virulence and fitness
}

\author{
Matteo Cerboneschi ${ }^{\mathrm{a}}$, Francesca Decorosi ${ }^{\mathrm{b}}$, Carola Biancalani ${ }^{\mathrm{a}}$, Maria Vittoria Ortenzi ${ }^{\mathrm{a}}$, \\ Sofia Macconi ${ }^{\mathrm{a}}$, Luciana Giovannetti ${ }^{\mathrm{b}}$, Carlo Viti ${ }^{\mathrm{b}}$, Beatrice Campanella ${ }^{\mathrm{c}}$, Massimo Onor ${ }^{\mathrm{c}}$, \\ Emilia Bramanti ${ }^{c}$, Stefania Tegli ${ }^{\text {a, } *}$ \\ ${ }^{a}$ Dipartimento di Scienze delle Produzioni Agroalimentari e dell'Ambiente, Laboratorio di Patologia Vegetale Molecolare, Università degli Studi di Firenze, Via \\ della Lastruccia 10, 50019 Sesto Fiorentino (Firenze), Italy \\ ${ }^{\mathrm{b}}$ Dipartimento di Scienze Produzioni Agroalimentari e dell'Ambiente, Genexpress, Università degli Studi di Firenze, Via della Lastruccia 14, 50019 Sesto \\ Fiorentino (Firenze), Italy \\ ${ }^{\mathrm{c}}$ ICCOM CNR, Via G. Moruzzi 1, 56124 Pisa, Italy
}

Received 25 January 2016; accepted 1 September 2016

Available online 13 September 2016

\begin{abstract}
The plant pathogenic bacterium Pseudomonas savastanoi, the causal agent of olive and oleander knot disease, uses the so-called "indole-3acetamide pathway" to convert tryptophan to indole-3-acetic acid (IAA) via a two-step pathway catalyzed by enzymes encoded by the genes in the iaaM/iaaH operon. Moreover, pathovar nerii of $P$. savastanoi is able to conjugate IAA to lysine to generate the less biologically active compound IAA-Lys via the enzyme IAA-lysine synthase encoded by the iaaL gene. Interestingly, iaaL is now known to be widespread in many Pseudomonas syringae pathovars, even in the absence of the iaaM and iaaH genes for IAA biosynthesis.

Here, two knockout mutants, $\Delta i a a L$ and $\Delta i a a M$, of strain Psn23 of P. savastanoi pv. nerii were produced. Pathogenicity tests using the host plant Nerium oleander showed that $\triangle i a a L$ and $\triangle i a a M$ were hypervirulent and hypovirulent, respectively and these features appeared to be related to their differential production of free IAA. Using the Phenotype Microarray approach, the chemical sensitivity of these mutants was shown to be comparable to that of wild-type Psn23. The main exception was 8 hydroxyquinoline, a toxic compound that is naturally present in plant exudates and is used as a biocide, which severely impaired the growth of $\Delta i a a L$ and $\Delta i a a M$, as well as growth of the non-pathogenic mutant $\Delta h r p A$, which lacks a functional Type Three Secretion System (TTSS). According to bioinformatics analysis of the Psn23 genome, a gene encoding a putative Multidrug and Toxic compound Extrusion (MATE) transporter, was found upstream of iaaL. Similarly to iaaL and iaaM, its expression appeared to be TTSS-dependent. Moreover, auxin-responsive elements were identified for the first time in the modular promoters of both the $i a a L$ gene and the $i a a M / i a a H$ operon of $P$. savastanoi, suggesting their IAA-inducible transcription. Gene expression analysis of several genes related to TTSS, IAA metabolism and drug resistance confirmed the presence of a concerted regulatory network in this phytopathogen among virulence, fitness and drug efflux.
\end{abstract}

(C) 2016 Institut Pasteur. Published by Elsevier Masson SAS. All rights reserved.

Keywords: Pseudomonas savastanoi; Phenotype microarray (PM); Indole-3-acetic acid; IAA-lysine synthase; Type three secretion system; Multidrug and toxic compound extrusion (MATE)

\section{Introduction}

Auxins are an essential class of phytohormones that play a crucial role in virtually all aspects of plant development and growth, as well as in the response of plants to environmental stimuli, including biotic and abiotic stresses [1,2]. The main naturally occurring auxin in plants is indole-3-acetic acid (IAA), the homeostasis of which guarantees its versatile role in

\footnotetext{
* Corresponding author.

E-mail address: stefania.tegli@unifi.it (S. Tegli).
} 
plants mediated by a complex network of processes related to its biosynthesis, catabolism, reversible conjugation, signaling and transport [3]. IAA is biosynthesized through several pathways from tryptophan (Trp), but Trp-independent routes are also known [4-7]. The free form of IAA is considered to be biologically active. However, in almost every plant tissue, this hormone is mostly conjugated, mainly to amino acids and sugars, and thus it is not more active [8,9]. IAA-conjugating enzymes, such as those encoded by the family of $G H 3$ plant genes, contribute to the maintenance of cellular IAA homeostasis and bioactivity via an inhibitory feedback loop [8]. The dynamic regulatory role played by IAA, from the whole plant to the cellular level, also relies on rapid and specific alterations of the transcriptional activation of auxin-responsive genes according to the distinct thresholds of IAA, through the so-called "auxin response element" (AuxRE), which is always present in their promoters [10-12]. Additionally, the transport and asymmetric distribution of IAA throughout the plant is dynamically modified in response to internal and external stimuli, mainly by the polar active transport (PAT) of IAA from cell to cell, which is mediated by changes in the expression and localization of specific plasma membrane-localized proteins (i.e. PIN, AUX), transporting IAA out of and into the plant cell, respectively [13]. Therefore, local IAA biosynthesis is dynamically integrated across the plant with mechanisms for its active transport, signaling and perception, the regulation of which results in specific response outputs to nearly any endogenous and environmental input [14].

Recently, several studies have shed light on the molecular basis of the role of IAA in plant-pathogen interactions, and particularly on the strategies adopted by phytopathogens to manipulate auxin homeostasis in plants to promote the infection process [15-18]. Basically, the localized increase in IAA during the first stages of their interaction with the host has been shown to be pivotal for plant pathogenic bacteria belonging to the Pseudomonas syringae group to promote plant susceptibility to infection [19-22]. In fact, $P$. syringae has also been demonstrated to take advantage of the accumulation in Arabidopsis-infected plants of an irreversibly catabolic conjugated form of IAA, IAA-Asp. Although it is less active in the plant than the free form, IAA-Asp has been shown to promote disease development by increasing $P$. syringae progression into the plant following transcription of its virulence genes, as also observed for the plant pathogenic fungus Botrytis cinerea [15,23]. Several of the $P$. syringae effectors secreted by the Type Three Secretion System (TTSS) have been shown to highjack the host plant systems for auxin biosynthesis, signaling and transport, to suppress active immune responses in susceptible plants [23-25].

Many plant-associated bacteria, including phytopathogens and symbionts, can also synthesize IAA using Trp as the main precursor [9,26]. This feature was initially incorrectly believed to be restricted to gall-producing bacteria such as Pseudomonas savastanoi and Pantoea agglomerans, in which IAA secretion was considered to be the main factor directly supporting the development of the hyperplastic symptoms on the host $[27,28]$. However, it soon became evident that a broader distribution of IAA biosynthesis was also present in several non-gall-inducing phytopathogenic bacteria such as Dickeya dadantii [29]. The best characterized Trp-dependent pathway in bacteria is the two-step process denoted as the indole-3acetamide (IAM) pathway, where the enzymes tryptophan-2monooxygenase (IaaM) and IAM hydrolase (IaaH) are encoded by the $i a a M$ and $i a a H$ genes, respectively, and sequentially convert Trp to IAM and then to IAA. This is the most common pathway in phytopathogenic bacteria, including $P$. savastanoi, in which the presence of the iaaL gene encoding the enzyme that conjugates IAA to the amino acid lysine to give IAA-Lys was first demonstrated [30]. This gene is widely distributed and conserved among $P$. syringae sensu lato species and pathovars, and no significant homology with any plant IAA-conjugating enzyme has been found [31]. Moreover, no plant hydrolases have been discovered to date for the catabolism of IAA-Lys, whereas several plant-associated bacteria have been shown able to hydrolyze plant auxin conjugates such as IAA-Asp [8].

In this work, Phenotype Microarray (PM) technology was applied for the first time to $P$. savastanoi to test its chemical sensitivity patterns. Knockout mutants of strain Psn23 of $P$. savastanoi pv. nerii, with impaired IAA synthesis, conjugation or TTSS functionality, were all found to be more sensitive to 8 hydroxyquinoline (8-HQ) than their wild-type counterpart. Overall, the data obtained herein also offer the opportunity to unveil functional links among IAA metabolism, TTSS and drug efflux in $P$. savastanoi pv. nerii, and they provide information that could be useful in the near future for development of alternative strategies for control of this plant pathogenic bacterium.

\section{Materials and methods}

\subsection{Bacterial strains and growth conditions}

The $P$. savastanoi strain $P s n 23$ and its mutants used in this study are listed in Table 1 . They were routinely grown at $26{ }^{\circ} \mathrm{C}$ as liquid or solid cultures, in King's B (KB) [32] or in hrpinducing minimal medium (MM) [33]. Bacterial growth was monitored by determining the culture optical density at $600 \mathrm{~nm}$ $\left(\mathrm{OD}_{600}\right)$ at different times during incubation, and bacterial concentrations were estimated by serial dilutions and plate counts. For long-term storage, the bacteria were maintained at $-20{ }^{\circ} \mathrm{C}$ and $-80{ }^{\circ} \mathrm{C}$ in $40 \%$ (v/v) glycerol. Escherichia coli strains TOP10 and ER2925 were grown in Luria-Bertani (LB) liquid or agarose medium [34]. Antibiotics, when required, were added to the medium at the following concentrations: $20 \mu \mathrm{g} / \mathrm{ml}$ streptomycin, $50 \mu \mathrm{g} / \mathrm{ml}$ nitrofurantoin, $10 \mu \mathrm{g} / \mathrm{ml}$ gentamicin and $50 \mu \mathrm{g} / \mathrm{ml} \mathrm{kanamycin.} \mathrm{Any} \mathrm{bacterial} \mathrm{contami-}$ nation was excluded by periodic monitoring using PCR-based assays specific for $P$. savastanoi $[35,36]$.

\subsection{Molecular techniques}

PCR, restriction digestion, ligation, DNA electrophoresis and transformation were performed according to standard 
Table 1

Bacterial strains, mutants and plasmids used in this study.

\begin{tabular}{|c|c|c|}
\hline Strain/Plasmid & Relevant characteristics & Reference/Source \\
\hline \multicolumn{3}{|l|}{ Strain } \\
\hline E. coli $\mathrm{TOP} 10$ & $\begin{array}{l}\text { F-, mcrA, } \Delta \text { (mrr-hsdRMS-crBC) } \Phi 80 \text { lacZ } \Delta \text { M15 } \Delta \text { lacX74 recA1 araD139 } \\
\Delta \text { (araleu)7697 galU galK rpsL (StrR) endA1 nupG }\end{array}$ & Invitrogen, Carlsbad, USA \\
\hline E. coli ER2925 & $\begin{array}{l}\text { ara-14 leuB6 fhuA31 lacY1 tsx } 78 \text { glnV44 galK2 galT22 mcrA dcm-6 hisG4 rfbD1 } \\
\text { R(zgb210::Tn10)TetS endA1 rpsL136 dam13::Tn9 xylA-5 } \\
\text { mtl-1 thi-1 mcrB1 hsdR2 }\end{array}$ & NEB, Hertfordshire, UK \\
\hline P. savastanoi pv. nerii (Psn23) & Wild type & This study \\
\hline$\Delta h r p A$ & hrpA in-frame deletion mutant of Psn23 & This study \\
\hline$\Delta i a a M$ & iaaM in-frame deletion mutant of Psn23 & This study \\
\hline$\Delta i a a L$ & iaaL in-frame deletion mutant of $P \operatorname{sn} 23$ & This study \\
\hline \multicolumn{3}{|l|}{ Plasmid } \\
\hline pK18mobsacB & sacB, lacZa, Km, mcs mobilizable vector & Schafer et al., 1994 \\
\hline$p K 18-\Delta h r p A$ & pK18mobsacB derivative, in-frame deletion of the $h r p A$ gene ( $273 \mathrm{bp}$ ) & This study \\
\hline 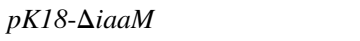 & pK18mobsacB derivative, in-frame deletion of the iaaM gene (1101 bp) & This study \\
\hline pK18- $\Delta i a a L$ & $\mathrm{pK} 18 \mathrm{mobsacB}$ derivative, in-frame deletion of the iaaL gene (561 bp) & This study \\
\hline
\end{tabular}

procedures [37]. The plasmids used and those generated in this work are listed in Table 1. Genomic DNA from P. savastanoi strains was extracted from single bacterial colonies using thermal lysis [37], or from bacterial cultures $\left(\mathrm{OD}_{600}=0.8\right)$ using the Puregene ${ }^{\circledR}$ Genomic DNA Purification Kit (Gentra Systems Inc., Minneapolis, MN, USA) according to the manufacturers' instructions. The DNA concentration was evaluated both spectrophotometrically with a NanoDrop ${ }^{\mathrm{TM}}$ ND-1000 (NanoDrop Technologies Inc., DE, USA) and visually by standard agarose gel electrophoresis [1\% agarose (w/v) in TBE 1X] [37]. For plasmid DNA extraction, NucleoSpin $^{\circledR}$ plasmid (Macherey-Nagel $\mathrm{GmbH}$ and Co. KG, Düren, Germany) was used according to the manufacturer's protocol. Amplicons were purified from agarose gel using NucleoSpin gel and PCR clean-up (Macherey-Nagel GmbH and Co.) and double-strand sequenced at Eurofins Genomics (Ebersberg, Germany). Multiple sequence alignments and comparisons were performed using the computer package CLUSTALW (version 2, http://www.ebi.ac.uk/Tools/ clustalw2) [38] and with the Basic Local Alignment Search Tool (BLAST, http://www.ncbi.nlm.nih.gov/blast) [39]. Primers were designed using Beacon Designer 7.7 software (Premier Biosoft International, Palo Alto, CA, USA) (Table 2). The 7548-bp sequence, containing genes iaaL, matE, iaaM and $i a a H$, was deposited in GenBank under accession number KU351686.

Table 2

Primers used in this study.

\begin{tabular}{ll}
\hline Primernname & Primer sequence $\left(5^{\prime} \rightarrow 3^{\prime}\right)$ \\
\hline hrpA_XbaI_For & TTTCTAGAATCTGTACTTTCGCCTTAA \\
hrpA_cross_Rev & CCGGATCCACTAAACTTAAACTCAGAGAACTTATGATGCTC \\
hrpA_cross_For & GTTTAAGTTTAGTGGATCCGGCCAGTTCTGATTTCTTGAATG \\
hrpA_EcoRI_Rev & TTGAATTCAAGTTATCTTCCTTGAGTTCG \\
iaaM_Xba_For & TTTTCTAGACAAAACCTTTACCGAATG \\
iaaM_cross_Rev & CCGGATCCACTAAACTTAAACTTTTTCAGGTAGTG \\
iaaM_cross_For & AAGTTTAGTGGATCCGGGCAGCGATTGTTTTTTCA \\
iaaM_EcoRI_Rev & TTTGAATTCCTGAGTTGACTGACAATC \\
iaaL_EcoRI_For & AAAGAATTCGTCATTCAGGTTGCTTTT \\
iaaL_cross_Rev & AAAGTTTAAGTTTAGTGGATCCGGGTTCTGAAGTCCTGATAAG \\
iaaL_cross_For & AAACCGGATCCACTAAACTTAAACTGAATACGAGTTTCTGTC \\
iaaL_XbaI_Rev & AAATCTAGAGATTTCGGCTATGATAAC \\
hrpA_RT_For & GCAGGGTATCAACAGCGTCAAG \\
hrpA_RT_Rev & CCGTTCTCTTCGTTCGCAGTG \\
iaaM_RT_For & TTCACTGCCTCACGGATAGCG \\
iaaM_RT_Rev & CGACTGGATGGTGGTGGGAAG \\
iaaL_RT_For & ACCTCAGCAGCGGCGTAAAG \\
iaaL_RT_Rev & TCGTCGGTGTGTATGGCAGTTC \\
iaaH_RT_For & TGATGATGCCGATATTGTC \\
iaaH_RT_Rev & AAGGTGGTGATTGATGATG \\
matE_RT_For & CATCGCAGCCATTACG \\
matE_RT_Rev & AGCCTGAAGAACCTGTC \\
hrpL_RT_For & GTATTGCGTTGAACCTGAT \\
hrpL_RT_Rev & CGTCTACCTGATGAGTGATA \\
hopAB1_RT_For & CGCAGGCATAATCATAGT \\
hopAB1_RT_Rev & CGGTTCAAGCGACATT \\
\hline
\end{tabular}




\subsection{Generation of Psn23 knockout mutants}

The $\Delta h r p A, \Delta i a a M$ and $\Delta i a a L$ mutants were constructed by in-frame deletion of the $h r p A$, iaaM and iaaL genes, respectively, from the Psn23 wild-type genome (Table 1), using marker exchange mutagenesis [40]. Knockout constructs were generated by overlap extension PCR using the primers listed in Table 2. The two DNA fragments flanking each inframe deletion were amplified from Psn23 genomic DNA as a template with $P f u$ polymerase (Promega Corp., Madison, WI, USA). The plasmids generated in this work are based on $p K 18 m o b s a c B$, a suicide vector for $P$. syringae sensu lato that allows SacB counterselection [12,13] and they are listed in Table 1. The recombinant vectors were transferred into electrocompetent Psn23 cells by electroporation with Gene Pulser $X_{\text {Xell }}{ }^{\mathrm{TM}}$ (Bio-Rad Laboratories Inc., Hercules, CA, USA) [41]. Suc ${ }^{\mathrm{R}}$ colonies were screened by PCR and the marked deletions were then confirmed by sequencing.

\subsection{Quantification of bacterial IAA synthesis}

The amount of IAA produced by $P$. savastanoi strains was assessed both by the Salkowski assay [42] and using highperformance liquid chromatography (HPLC). IAA, L-Trp, indole-3-acetamide (IAM) and LC-MS-grade acetonitrile, methanol and formic acid were purchased from Sigma-Aldrich, Inc. (St. Louis, MO, USA). The UniPrep ${ }^{\mathbb{B}}$ syringeless filtration device $(0.25 \mu \mathrm{m})$ was obtained from Agilent Technologies (Santa Clara, CA, USA). Standard stock solutions $(1000 \mu \mathrm{g} / \mathrm{ml})$ of IAA and IAM were prepared in methanol, while the standard Trp stock solution $(1000 \mu \mathrm{g} / \mathrm{ml})$ was prepared in ultra-pure Milli-Q water. Working solutions for each standard were prepared by appropriate dilution of the stock solution with $35 \% \mathrm{MeOH}$ and $0.1 \%$ formic acid. Samples were prepared from $0.1 \mathrm{~g}$ of lyophilized bacterial supernatant, resuspended in $1 \mathrm{ml}$ of $35 \% \mathrm{MeOH}$ and $0.1 \%$ formic acid, further diluted 1:10 in the same solvent and filtered using a $0.25-\mu \mathrm{m}$ Uniprep ${ }^{\circledR}$ syringeless filtration device. The filtrates were analyzed by HPLC-DAD/FD or HPLC-MS, with data acquisition and data analysis carried out by the ChromQuest ${ }^{\mathrm{TM}}$ 4.2 Chromatography Data System and MassHunter ${ }^{\circledR}$ Workstation Software (B.04.00), respectively.

\subsection{Arabidopsis root elongation assay}

Seeds of Arabidopsis thaliana Col-0 were surface-sterilized in $1 \%$ bleach, rinsed three times in sterile distilled water and then stratified at $4{ }^{\circ} \mathrm{C}$ for $2-4$ days to obtain uniform germination. The Arabidopsis Col-0 seedlings were then sown on new half-strength MS plates and grown in a vertical orientation. At $4 \mathrm{~cm}$ from the root tip, $15 \mu \mathrm{l}$ of a bacterial suspension $\left(\mathrm{OD}_{600}=0.5\right)$ of Psn 23 or of its mutants were spotted, as previously described [43]. Photographs were obtained after an additional 4 days of vertical growth and the root length was measured using ImageJ software. The length of newly elongated roots was measured and the relative root length was calculated. The mean \pm standard deviation (SD) for 10 to 15 seedlings was calculated and each assay was repeated at least three times.

\subsection{Pathogenicity tests}

In vitro micropropagated oleander (Nerium oleander L.) plants with red double flowers (Vitroplant Italia s.r.l., Cesena, Italy) were grown for 3 weeks at $26{ }^{\circ} \mathrm{C}$ on Murashige-Skoog medium (MS) [44], without the addition of phytohormones and with a photoperiod of 16-h light/8-h dark. The plants were then wounded on the stem at the second internode using a 1-ml syringe needle and immediately inoculated with $1 \mu \mathrm{l}$ of a bacterial suspension in sterile physiological solution (SPS, $0.85 \% \mathrm{NaCl}$ in distilled water), with an $\mathrm{OD}_{600}=0.5$ (approximately $0.5 \times 10^{8}$ colony forming unit $/ \mathrm{ml}, \mathrm{CFU} / \mathrm{ml}$ ). Negative control plants were inoculated with SPS alone. The plants were then incubated at $26{ }^{\circ} \mathrm{C}$ under a 16 -h light/8-h dark photoperiod and periodically monitored for the appearance of symptoms. Photographic records were obtained at 7, 14 and 21 days post-inoculation (dpi). At the same time points, bacterial growth was also estimated as previously described [36,45]. Three independent experiments were performed and nine plants for each P. savastanoi strain were inoculated in each run.

\subsection{Hypersensitive response assays}

As a model plant for the hypersensitive response (HR) assay, Nicotiana tabacum var. Burley White was used. The plants were grown at $24{ }^{\circ} \mathrm{C}$ with a relative humidity of $75 \%$ and a photoperiod of 16/8-h light/dark. Bacterial cultures were grown overnight in $\mathrm{KB}$ medium at $26^{\circ} \mathrm{C}$ and resuspended in SPS $\left(\mathrm{OD}_{600}=0.5\right)$. The final bacterial cell concentration was confirmed by the serial dilution agar plating method. Using a 2-ml blunt-end syringe, approximately $100 \mu \mathrm{l}$ of the bacterial suspension was infiltrated into the abaxial mesophyll of fully expanded leaves of three tobacco plants [46], with six replicates tested per strain in each of the three independent experiments. The development of HR was assessed according to the presence of macroscopic tissue collapse at $24 \mathrm{~h}$ postinoculation. Photographic records of the results were obtained.

\subsection{Phenotype Microarray (PM)}

P. savastanoi strains were tested on chemical sensitivity panels (PM09-PM20) using PM technology (Biolog Inc., Hayward, CA, USA). Overall 1152 different conditions were tested, including several concentrations of osmolytes (PM09), $\mathrm{pH}$ stresses (PM10) and a wide variety of potentially toxic compounds (PM11-20). In the PM11-20 panels, each chemical is dispensed at four increasing concentrations in adjacent wells, from the lowest to the highest. The complete list of compounds assayed can be obtained at http://www.biolog. com/pdf/pm_lit/PM1-PM10.pdf and http://www.biolog.com/ pdf/pm_lit/PM11-PM20.pdf. PM uses tetrazolium violet reduction as a reporter of active metabolism [47]. Reduction of the dye causes the formation of a purple color that, recorded every 15 min, provides quantitative and kinetic information 
about the response of the bacterial cells to each compound [47]. Each strain was grown overnight at $26^{\circ} \mathrm{C}$ on BUG agar (Biolog, Inc.). Colonies were picked using a sterile cotton swab and suspended in SPS. The cell density was adjusted to $81 \%$ transmittance $(\mathrm{T})$ on a turbidimeter (Biolog, Inc.). The bacterial suspension was diluted twelve times in $\mathrm{KB}$ medium supplemented with $25 \mathrm{mM} \mathrm{L-Trp}$ and $1 \times$ dye A (Biolog Inc.). All plates were incubated at $26{ }^{\circ} \mathrm{C}$ in an Omnilog reader (Biolog, Inc.) and the readings were recorded for $96 \mathrm{~h}$. Kinetic data were analyzed using Omnilog-PM software (release OM_PM_109M). For each strain, the area of the kinetic curves detected in PM9-20 was exported and used to calculate the difference between the wild-type and each mutant. Differences greater than 40,000 Arbitrary Omnilog Units (AOU) were considered relevant to identify phenotypic differences between the wild-type and each of its mutants.

\subsection{Quantitative gene expression analysis}

Bacterial gene expression was evaluated by real-time PCR. Bacterial cells of wild-type $P s n 23$ and its mutants were grown overnight in $\mathrm{KB}$ (starting concentration $\mathrm{OD}_{600}=0.1$ ), washed twice with SPS and transferred into MM alone or supplemented with L-Trp $(250 \mu \mathrm{M})$, IAA $(200 \mu \mathrm{M}), 8$-HQ $(10 \mu \mathrm{M})$, or IAA +8 -HQ $(200 \mu \mathrm{M}$ and $10 \mu \mathrm{M}$, respectively). Cells were collected after $24 \mathrm{~h}$ of incubation at $26{ }^{\circ} \mathrm{C}$ with shaking $(100 \mathrm{rpm})$ and used for RNA extraction performed with a NucleoSpin ${ }^{\circledR}$ RNA Plus (Macherey-Nagel GmbH and Co. KG, Düren, Germany). Residual genomic DNA was removed using a NucleoSpin ${ }^{\circledR}$ gDNA Removal Column (Macherey-Nagel $\mathrm{GmbH}$ and Co.). RNA Reverse transcription was performed using the iScript ${ }^{\mathrm{TM}}$ Advanced cDNA synthesis kit (Bio-Rad Laboratories Inc.) with approximately $2 \mu \mathrm{g}$ of total RNA. Diluted cDNA was analyzed with SsoFast ${ }^{\mathrm{TM}}$ EvaGreen $^{(}$ Supermix (Bio-Rad Laboratories Inc.), using the CFX96 cycler - real-time PCR detection system and CFX-manager software v1.6 (Bio-Rad, Laboratories Inc.). To normalize the expression of each gene, the 16S rDNA expression level was used as a housekeeping gene. For each sample, three replicates were assessed and three independent experiments were conducted. The primers used are listed in Table 2.

\subsection{Data analysis}

Statistically significant differences among treatments were calculated by one-way ANOVA with the Tukey-Kramer posttest $(\mathrm{p}<0.05)$ with PAST software (Version 3.11, Øyvind Hammer, Natural History Museum, University of Oslo).

\section{Results}

\subsection{A prokaryotic AuxRE identified in the promoters of genes for IAA biosynthesis and conjugation in $\mathrm{P}$. savastanoi $p v$. nerii}

In the Psn23 genome, the iaaM/iaaH operon for IAA biosynthesis is positioned in close proximity to the iaaL gene for IAA conjugation, flanking an insertion sequence of the IS4 family on a 7548-bp DNA fragment. Moreover, an ORF encoding a putative Multidrug and Toxic compound Extrusion (MATE) efflux transporter is located upstream of $i a a L$ (Fig. 1A), hereafter denoted matE. According to in silico analysis, the $i a a L$ and $m a t E$ genes are divergently transcribed from the iaaM/iaaH operon. In the $5^{\prime}$ region of the iaaM/iaaH operon, as well as upstream of iaaL and matE, hrp box promoter sequences were found, suggesting their TTSSdependent expression and HrpL-regulated transcription (Fig. 1B). However, several substitutions are present on the first 5 nucleotides of the -35 consensus motif (GGAACC) and the first 4 nucleotides of the -10 motif (CCACNNA) of these promoters in comparison to the canonical hrp-box driving hrpA transcription in P. syringae sensu lato (Fig. 1B). Additionally, other regulatory elements were found that have never been identified previously in $P$. savastanoi or in any other $P$. syringae sensu lato. In particular, a putative prokaryotic AuxRE was identified upstream of the iaaL gene and the iaaM/iaaH operon of Psn23. The short sequence (TGTCCA) resembles that located upstream of the ipdC gene of Azospirillum brasiliense, encoding the key enzyme for Trp-dependent IAA biosynthesis in this bacterium and the only prokaryotic AuxRE identified to date [48]. With respect to the start codon for iaaL, the AuxRE motif is located at positions -38 to -33 . Moreover, in the iaaL promoter, a dyadic sequence (DS) has also been identified between positions -42 and -71 , characterized by a perfect 8 -bp inverted repeat separated by a 14-bp spacer, further supporting the auxin-inducible expression of iaaL in $P$. savastanoi. Conversely, no DS was found associated with the putative AuxRE in the promoter of the iaaM/iaaH operon (Fig. 1A). Using in silico analysis of the $5^{\prime}$ region of the $i a a L$ gene and the iaaM/iaaH operon in other $P$. syringae phytopathogens, putative AuxREs were also identified in $P$. savastanoi pv. nerii (EW 2009, CFBP5067 and ICMP16943), while a DS sequence was found only in P. syringae pv. tomato DC3000 (data not shown).

\subsection{An increase in free IAA secretion determines the hypervirulence of the $\Delta \mathrm{iaaL}$ mutant}

After 24 and $48 \mathrm{~h}$ of growth on MM amended with L-Trp $(250 \mu \mathrm{M})$, indole production was evaluated in the culture supernatants of $P s n 23$ and mutants $\Delta i a a M$ and $\Delta i a a L$. Given the presence of several $h r p$ box motifs in promoters of the genes for IAA synthesis and conjugation, mutant $\Delta h r p A$ was also examined for comparison. The colorimetric Salkowski assay was used for initial screening because it is able to detect IAA with high specificity among other indoles (Fig. S1). As expected, indole production by $\triangle i a a M$ was negligible. Conversely, mutant $\Delta i a a L$ produced significantly higher amounts of IAA than the wild-type Psn23, with approximately 61.3 and $64.5 \mu \mathrm{g} / \mathrm{ml}$ of IAA equivalents after 24 and $48 \mathrm{~h}$ of growth, respectively. Regarding $\triangle h r p A$, IAA biosynthesis was comparable to that of $P \sin 23$ (approximately 40 and $37 \mu \mathrm{g} / \mathrm{ml}$ of IAA equivalents after $24 \mathrm{~h}$ and $48 \mathrm{~h}$ of 


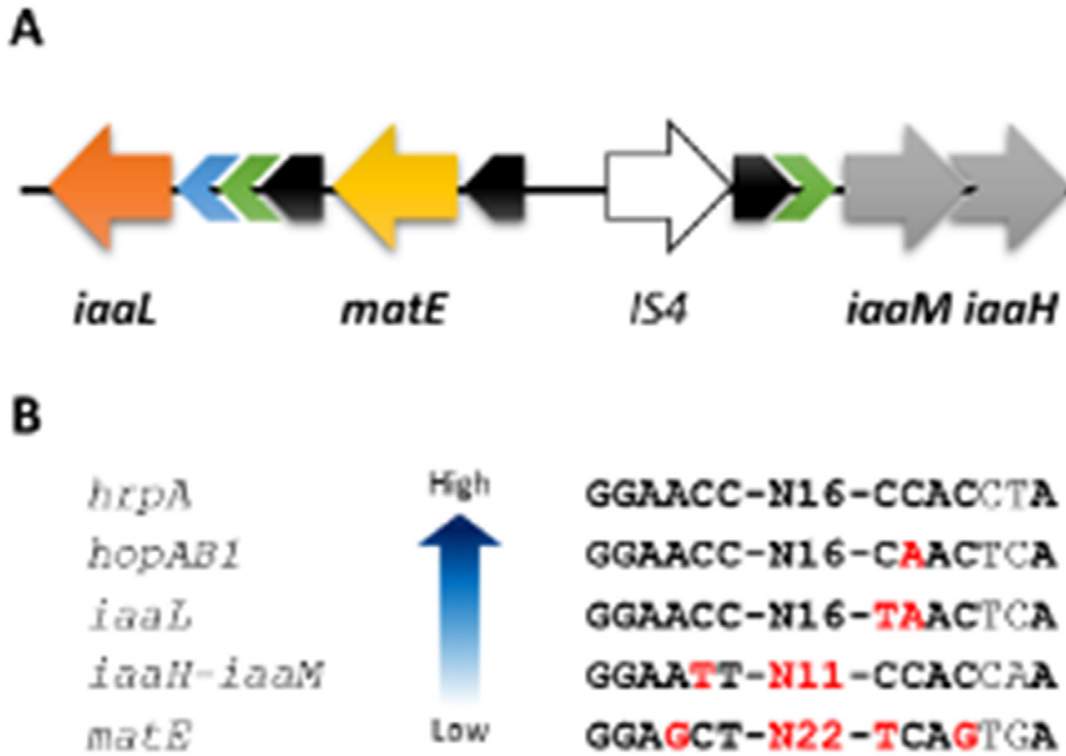

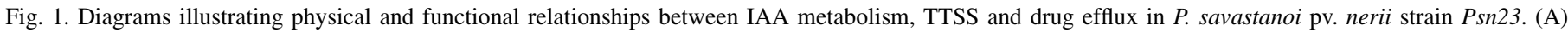

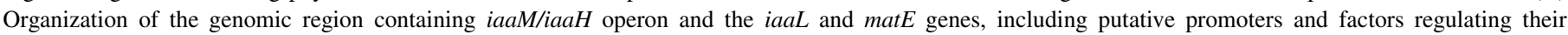

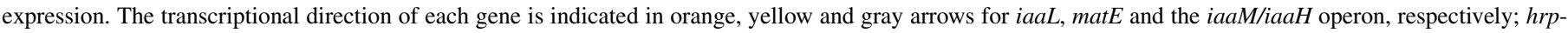

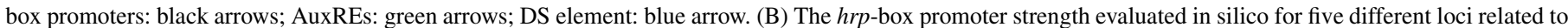

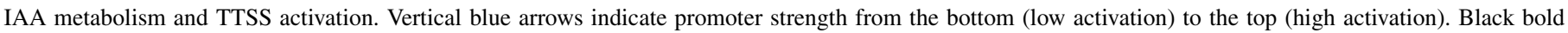
nucleotides indicate perfect identity with the hrpA promoter; red bold nucleotides underline specific mismatches.

growth, respectively). These results were then confirmed using an innovative method developed in this work that is based on liquid chromatography coupled to molecular fluorescence and tandem mass spectrometry, specifically, high resolution QToF. The fluorescence chromatograms at $340 \mathrm{~nm}$ $\left(\lambda_{\mathrm{ex}}=280 \mathrm{~nm}\right)$ of Trp, IAA and IAM used herein as standards $(1 \mu \mathrm{g} / \mathrm{ml})$ were compared with those from the lyophilized supernatants of $P s n 23$ and its three mutants $\Delta i a a M$, $\triangle i a a L$ and $\triangle h r p A$. In particular, the fluorescence chromatograms for Trp and for IAA displayed a peak with a retention time of $2.68 \mathrm{~min}$ and $12.7 \mathrm{~min}$, respectively. As expected, $\triangle i a a M$ was unable to convert Trp into IAA, and thus the peak at $2.68 \mathrm{~min}$ was present, while that at $12.7 \mathrm{~min}$ was absent (Fig. S2). Conversely, the $\Delta i a a L$ chromatogram showed both peaks for Trp and IAA. Surprisingly, both Psn23 and its $\triangle h r p A$ mutant exhibited the peak corresponding to Trp $(2.68 \mathrm{~min})$, but not that at $12.7 \mathrm{~min}$ for IAA. Moreover, another unexpected signal was a retention time of $3.28 \mathrm{~min}$ that was not attributable to any of the standards used herein. Both $P s n 23$ and $\triangle h r p A$ have the ability to convert IAA to IAA-Lys, unlike $\triangle i a a L$. Thus, it was hypothesized that the peak at $3.28 \mathrm{~min}$ corresponded to IAA-Lys. Unfortunately, there is no commercially available standard for IAA-Lys and this analyte requires further characterization by HPLC-ESIQ-ToF. Fig. S3 shows the mass spectrum, acquired using positive ionization, for this unidentified indolic compound. The presence of $\mathrm{m} / \mathrm{z} 304\left([\mathrm{M}+\mathrm{H}]^{+}\right)$and $130\left(\left[\mathrm{NH}_{2^{-}}\right.\right.$ $\left.\left.\left(\mathrm{CH}_{2}\right)_{4}-\mathrm{CH}-\mathrm{COOH}\right]^{+}\right)$unequivocally confirmed that this compound corresponded to IAA-Lys.
The higher content of free IAA in the $\Delta i a a L$ mutant in comparison to the wild-type Psn 23 was also biologically and quantitatively demonstrated by analyzing the effect of bacterial IAA on root elongation and lateral root formation in $A$. thaliana seedlings (Fig. 2). After 14 days, the mean length of the main root in the $\Delta i a a M$-treated seedlings was $6.92 \pm 0.46 \mathrm{~cm}$, which is comparable to that obtained for untreated seedlings $(6.782 \pm 0.34)$. Similarly, the mean root length of the $\Delta h r p A$-treated seedlings $(5.50 \pm 0.46 \mathrm{~cm})$ was longer than that of wild-type Psn23-treated seedlings $(3.78 \pm 0.13 \mathrm{~cm})$. Conversely, the mean length of the roots of A. thaliana seedlings treated with $\Delta i a a L$ was extremely reduced $(2.57 \pm 0.06 \mathrm{~cm})$. Overall, these data biologically confirmed the higher levels of free IAA produced by the $\triangle i a a L$ mutant in comparison to Psn23, inducing strong inhibition of root elongation. As expected, this effect was not observed in A. thaliana seedlings treated with the $\Delta$ iaaM mutant, which is unable to synthesize IAA. According to the bimodal and opposite effect of the free IAA concentration on the primary root length and local differentiation events, massive lateral root development was also observed following $\triangle i a a L$ treatment (Fig. 2).

Given the high production of free IAA by the $\Delta i a a L$ mutant, and considering the conflicting results reported to date regarding the role of the iaa $L$ gene in the virulence of $P$. syringae sensu lato, pathogenicity trials were subsequently conducted using micropropagated oleander plants. Together with $\triangle i a a L$, the wild-type Psn 23 and mutants $\triangle i a a M$ and $\triangle h r p A$ were also used for comparison. The development of 


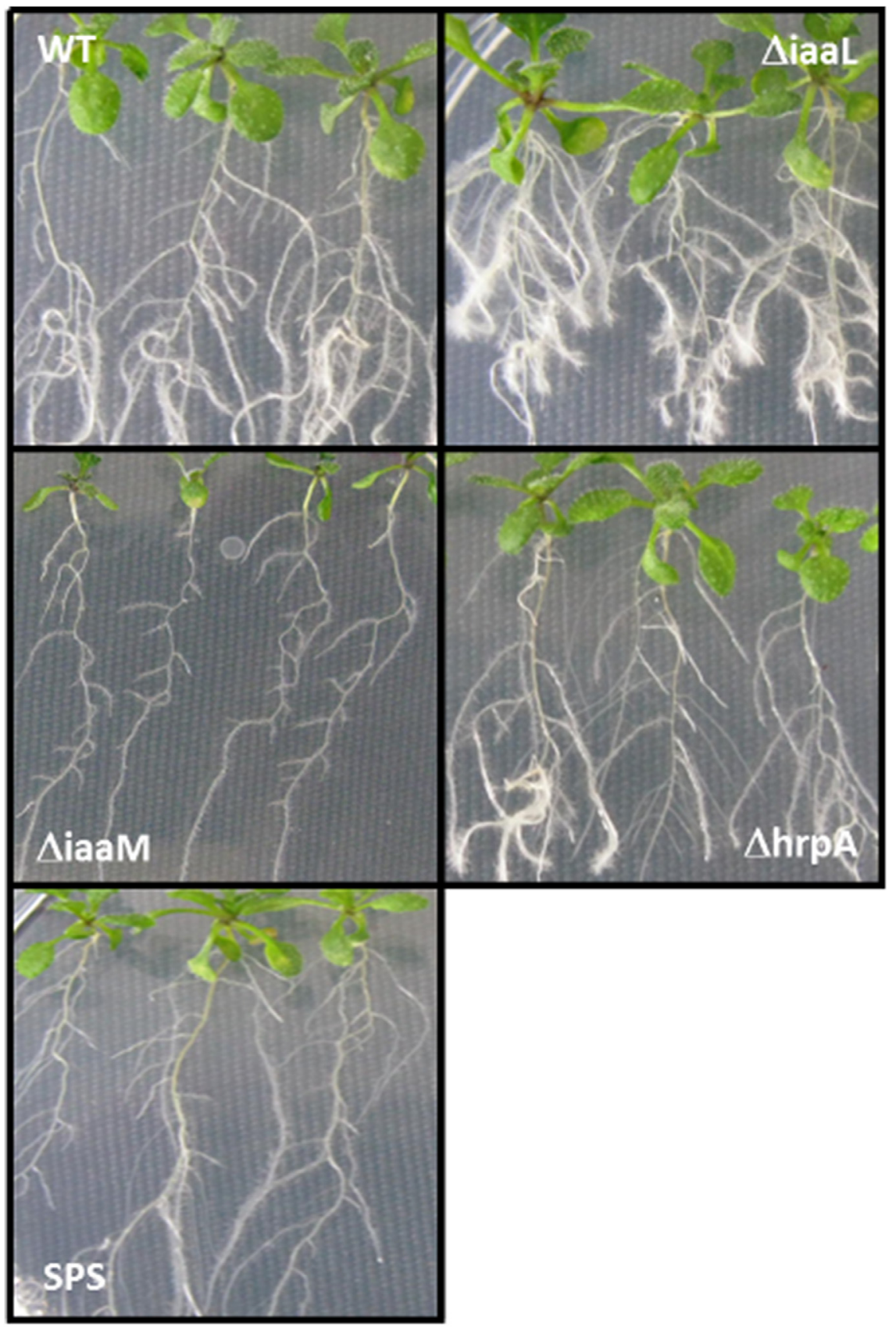

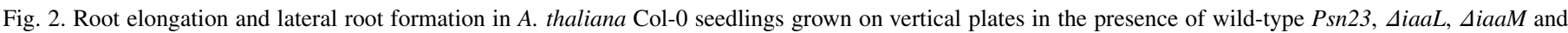
$\triangle$ hrpA supernatants.

hyperplastic symptoms was visually observed and recorded at 7, 14 and 21 dpi (Fig. 3A). At the same time points, in planta bacterial growth was also assessed (Fig. 3B). Mutant $\triangle i a a L$ consistently induced more extensive hyperplastic lesions than Psn23. The symptoms were not restricted to the inoculation site, as observed for Psn23, but the upper part of the plant was also affected. Bacterial multiplication in planta was significantly correlated with symptoms and disease severity, with $\triangle i a a L$ achieving higher CFU values than Psn23 at all time points considered (Fig. 3B). Conversely, hyperplastic symptoms and bacterial growth were drastically reduced or completely abolished in the case of $\triangle i a a M$ and $\triangle h r p A$, respectively, as expected (Fig. 3B). Concerning HR analysis of tobacco, $\Delta i a a M$ and $\Delta i a a L$ caused a typical HR, similar to that observed with $P s n 23$, while $\Delta h r p A$ did not. These results confirmed that $\triangle h r p A$ is not more pathogenic (Fig. S4).

\subsection{PM analysis as a tool for unraveling the} relationship in $\mathrm{P}$. savastanoi $p v$. nerii between IAA metabolism, TTSS and resistance to toxic compounds

Undoubtedly, the fitness in planta of a bacterial phytopathogen depends not only on its virulence and its ability to 
A

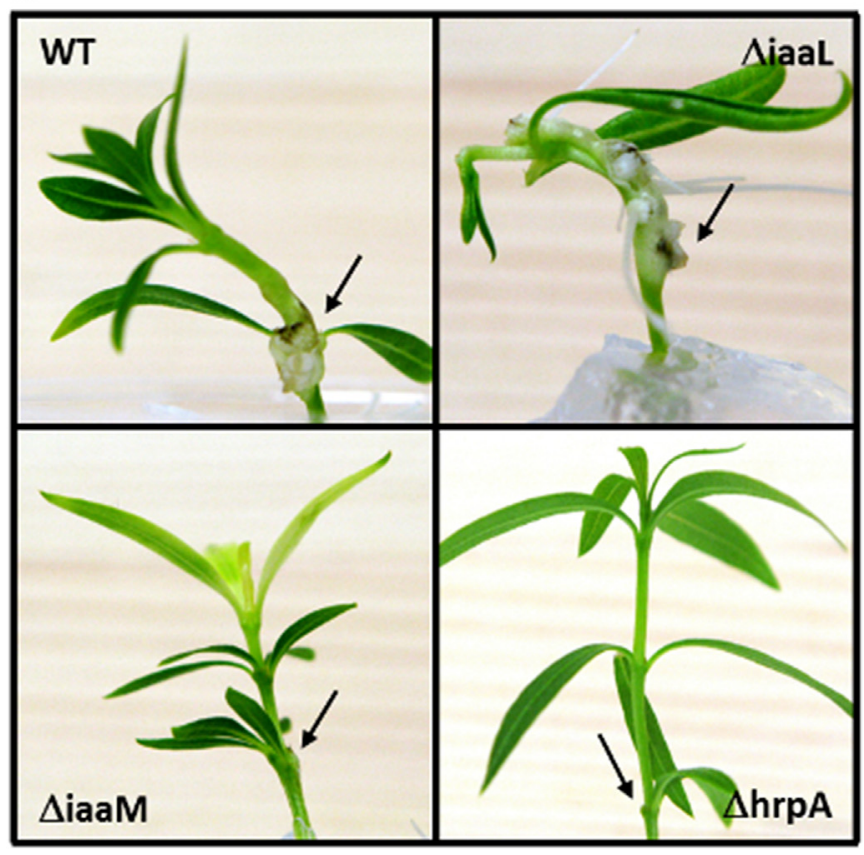

B

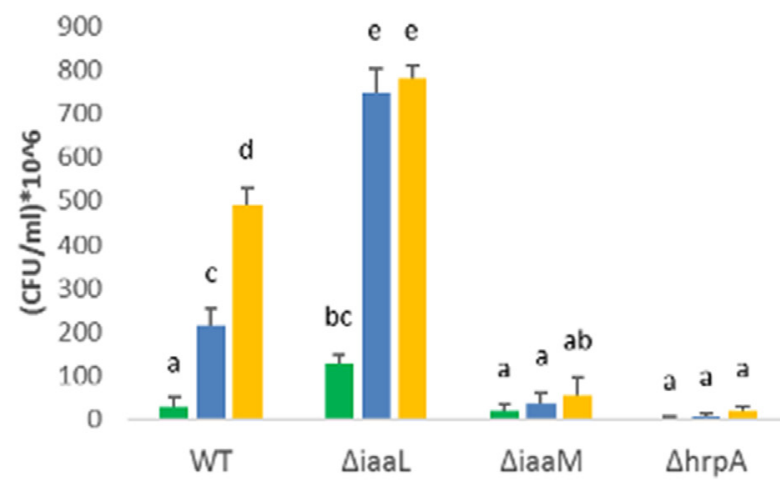

Fig. 3. Pathogenicity trials of micropropagated oleander plants conducted using $P s n 23$ and its mutants $\triangle i a a L, \triangle i a a M$ and $\triangle h r p A$. (A) Knot development at 21 days post-infection. Black arrows indicate the site of bacterial inoculum. (B) In planta bacterial growth at 7 (green), 14 (blue) and 21 (yellow) days post-infection. Values are the mean of 3 independent experiments with 9 replicates for each strain \pm standard deviation $(\mathrm{SD})$. ANOVA revealed statistically significant differences $(\mathrm{p}<0.05)$; comparisons using the Tukey posttest are indicated by letters, where different letters indicate statistically significant differences.

multiply in its hosts, but also on its resistance to a number of toxic and antimicrobial compounds of plant origin that are produced before and during the infection process.

As a result of the unexpected hypervirulence of the $\Delta i a a L$ mutant, we decided to investigate potential changes in the phenotype of this mutant in comparison to wild-type Psn23 that could justify its reduced fitness and competitiveness in nature. Moreover, the presence of a gene encoding a putative MATE upstream of $i a a L$ further prompted wide phenotypic screening. PM analysis was applied to strain Psn 23 and to its mutant $\triangle i a a L$. Mutants $\triangle i a a M$ and $\triangle h r p A$ were also included for comparison. By using twelve panels (PM9-PM20), their sensitivity to $\mathrm{pH}$, osmolytes and to 240 toxic chemicals, each at four different concentrations, was evaluated. The three mutants showed the same $\mathrm{pH}$ and osmolyte sensitivity profiles compared with wild-type Psn23. As main characteristics, they tolerated $\mathrm{pH}$ values higher than 5.5 , as well as $\mathrm{NaCl}$ concentrations lower than 4\%. Conversely, the sensitivity profiles of the mutant strains to toxic compounds did not completely overlap those of wild-type Psn 23 (Table 3). The most noticeable results were those obtained following 8-HQ treatment, in which the three mutants exhibited the same behavior. In particular, $\triangle i a a L, \triangle i a a M$ and $\triangle h r p A$ showed significantly higher sensitivity towards 8-HQ than Psn 23, although to different extents. The most sensitive strain was SiaaL.

Following these findings, the expression of matE, as well as of several genes related to IAA metabolism and to TTSS, was evaluated by real-time PCR and on Psn 23 grown in vitro on MM supplemented with 8-HQ. As shown in Fig. 4, the transcript levels of matE were the only ones to be upregulated in the presence of 8-HQ. Although this increase was quite marginal (1.5-fold), this result could support the hypothesis of 8-HQ efflux in Psn 23 mediated by the hypothetical transporter encoded by matE. Moreover, in the presence of 8-HQ, the expression levels of $m a t E$ were generally lower in the mutants compared with Psn23, explaining their higher sensitivity to this antimicrobial compound in PM experiments in Fig. 5A.

The expression of TTSS genes such as $h r p L$ and hopABl, induced by in vitro growth on MM, was strongly reduced in

Table 3

Difference between the areas of the kinetic curve of the wild type and the three mutant strains detected by PM technology.

\begin{tabular}{lllll}
\hline Compound & Dose $^{\mathrm{a}}$ & $\begin{array}{l}\mathrm{A}_{\text {wildtype }}- \\
\mathrm{A}_{\text {mutant } \Delta \text { iaaL }}\end{array}$ & $\begin{array}{l}\mathrm{A}_{\text {wildtype }}- \\
\mathrm{A}_{\text {mutant } \Delta \text { iaaM }}\end{array}$ & $\begin{array}{l}\mathrm{A}_{\text {wildtype }}- \\
\mathrm{A}_{\text {mutant }} \Delta \text { hrpA }\end{array}$ \\
\hline Oxytetracycline & I & 8350 & 8402 & 5597 \\
& II & 17,617 & 7658 & 3834 \\
& III & 18,276 & 17,675 & 9203 \\
8-Hydroxyquinoline & IV & 33,953 & $47,479^{\mathrm{b}}$ & 22,135 \\
& I & 4341 & 1210 & 4582 \\
& II & 5077 & 5214 & 3918 \\
Hydroxylamine & III & $56,283^{\mathrm{b}}$ & 7640 & 22,848 \\
& IV & $56,771^{\mathrm{b}}$ & $55,390^{\mathrm{b}}$ & $54,068^{\mathrm{b}}$ \\
& I & -6994 & 4551 & $-15,205$ \\
& II & 4304 & 334 & $-18,857$ \\
Sodium azide & III & 2638 & -7003 & $-27,870$ \\
& IV & 1130 & $-39,047$ & $-76,650^{\mathrm{b}}$ \\
& I & $-24,057$ & -3998 & $-61,490^{\mathrm{b}}$ \\
& II & 55 & -199 & -2452 \\
Polymixin B & III & -440 & -1675 & -2577 \\
& IV & 233 & -175 & -2253 \\
& I & 10,707 & 2512 & -7035 \\
& II & 5561 & 3181 & -6762 \\
& III & 964 & 1262 & 505 \\
& IV & 132 & -872 & $-57,193^{\mathrm{b}}$ \\
\hline
\end{tabular}

${ }^{a}$ Four increasing doses of the toxic compounds were tested, dose I is the lowest and dose IV is the highest.

b Differences higher than 40,000 AOU were considered relevant to identify phenotypic differences between the mutants and the wild type. 


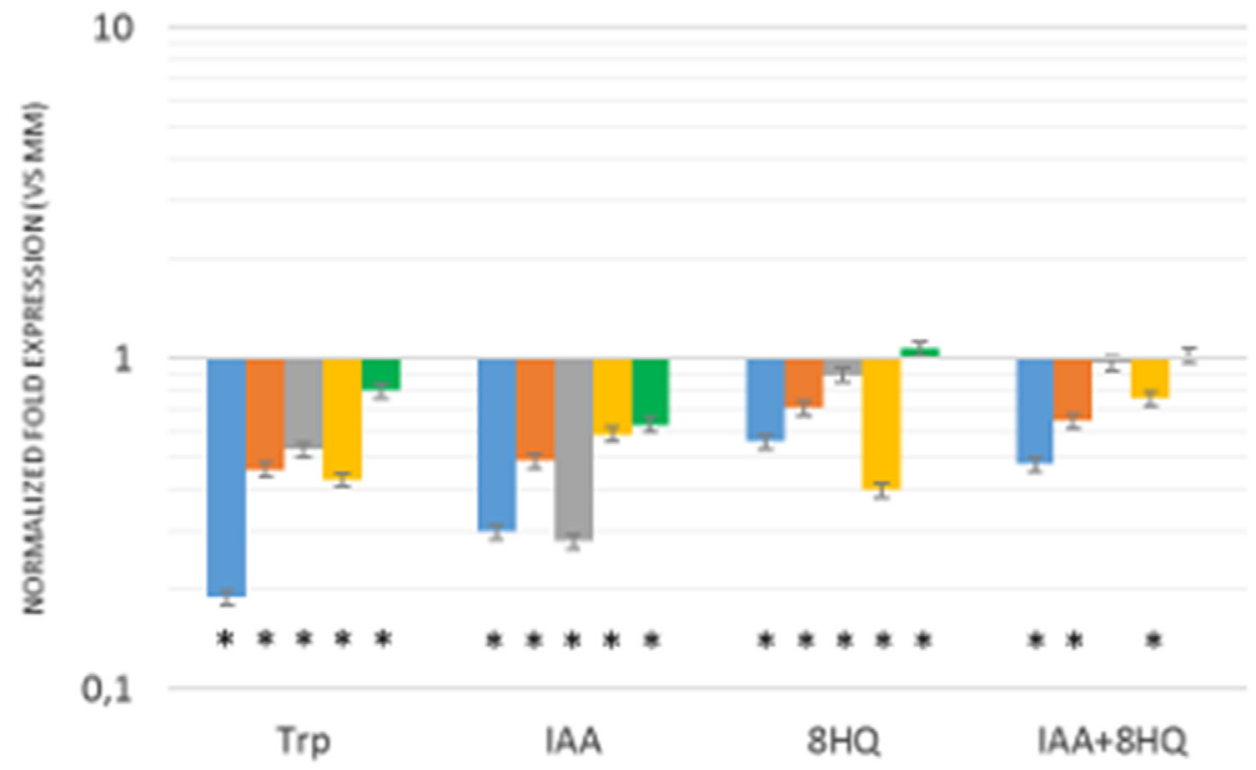

Fig. 4. Differential gene expression of wild-type Psn23 grown in vitro on MM alone or supplemented with L-Trp (250 $\mu \mathrm{M})$, IAA (200 $\mu \mathrm{M})$, 8-HQ (10 $\mu \mathrm{M})$ and IAA +8 -HQ $(200 \mu \mathrm{M}$ and $10 \mu \mathrm{M}$, respectively). Gene map: $h o p A B 1$ in blue, $h r p L$ in orange, $i a a H$ in gray, $i a a L$ in yellow and $m a t E$ in green. Data are averages of triplicates \pm standard deviation $(\mathrm{SD})$. Asterisks indicate significant differences compared with the untreated sample at $\mathrm{p}<0.05$.

wild-type Psn23 in the presence of IAA $(200 \mu \mathrm{M})$ (Fig. 4). This downregulation also occurred when MM was supplemented with $\operatorname{Trp}(250 \mu \mathrm{M})$, likely because IAA synthesis was carried out by Psn 23 using Trp as a precursor (Fig. 4). Likewise, the expression of genes such as $i a a H$, iaaL and matE was also reduced in response to IAA or Trp (Fig. 4), as expected for the presence of $h r p$ box motifs in their promoters (Fig. 1B). Surprisingly, the inhibition of TTSSregulated genes by IAA was largely removed when 8-HQ was applied together with IAA. These data suggest a further role for the putative MATE transporter encoded by $m a t E$, in addition to conferring resistance to drugs, mediating IAA efflux (Fig. 4). In support of this hypothesis, the expression levels of $m a t E$ were upregulated in $\triangle i a a M, \Delta i a a L$ and $\triangle h r p A$ mutants in comparison to wild-type $P s n 23$ when IAA was added to the MM (Fig. 5B). This result suggested a kind of repressive mechanism directly or indirectly driven by TTSS to activate drug or IAA efflux during specific stages of the infection process when TTSS is downregulated, or even switched off.

\section{Discussion}

IAA biosynthesis, as well as of that of many indoles, is widespread among Gram-positive and Gram-negative bacteria, as well as in many fungi, including many pathogens of plants and even humans [49]. Trp is mostly used as a precursor of IAA, essentially by the IAM or IPA pathway [50]. While the pivotal role of this phytohormone in development of hyperplastic symptoms caused by Ustilago maydis and $P$. savastanoi on their hosts [51], or for rhizobia and ectomycorrhizal fungi in supporting their beneficial interaction with plants is very clear [52], its physiological role in the presence of IAA produced by plant pathogenic necrotrophic fungi such as Colletotrichum and Fusarium spp. is less intuitive [53,54]. It is even less well understood when IAA biosynthesis occurs in bacteria and yeasts that are pathogenic to mammals, or that belong to different soil and aquatic ecosystems [55]. In fact, in the last few years, accumulating scientific evidence has indicated that IAA is indeed a signaling molecule for bacteria and is essential for regulation of their physiology, adaptation to stress conditions and communication, as well as mediation of several host-microbe interactions [49]. Although highly speculative, these findings are not surprising when considering that IAA has the same indole-like chemical structure as that of other eukaryotic hormones such as serotonin, melatonin and epinephrine [56].

Regarding plant-associated bacteria, IAA has been shown to determine changes in bacterial gene expression in the nongall-forming phytopathogen $D$. dadantii (formerly Erwinia herbicola) 3937 [57], in Agrobacterium tumefaciens [58,59] and in the plant growth-stimulating rhizobacterium A. brasilense [60], in which its ipdC gene has been the only bacterial gene reported to possess an AuxRE in its promoter, as observed in the auxin-responsive genes of plants [48]. Similarly, in the yeast Saccharomyces cerevisiae, several IAA-inducible genes are regulated at high IAA concentrations by the fungal transcriptional activator YAP-1, which is able to bind to their promoters to induce a switch towards invasive behavior, together with an arrest of cell growth. Conversely, at lower concentrations, IAA induces $S$. cerevisiae filamentation and adhesion, thus supporting plant infection. This phenotype conversion also involves a family of transporters, and it is noteworthy that YAP-1 is also pivotal for the pleiotropic drug resistance of $S$. cerevisiae [61]. 
10

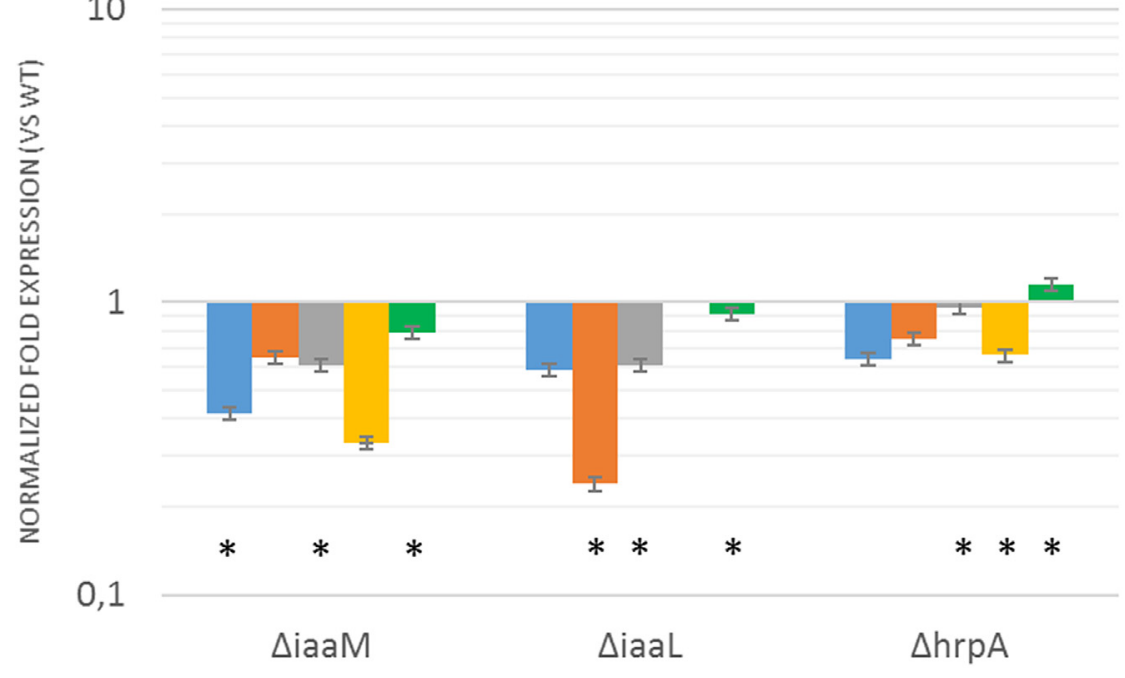

10

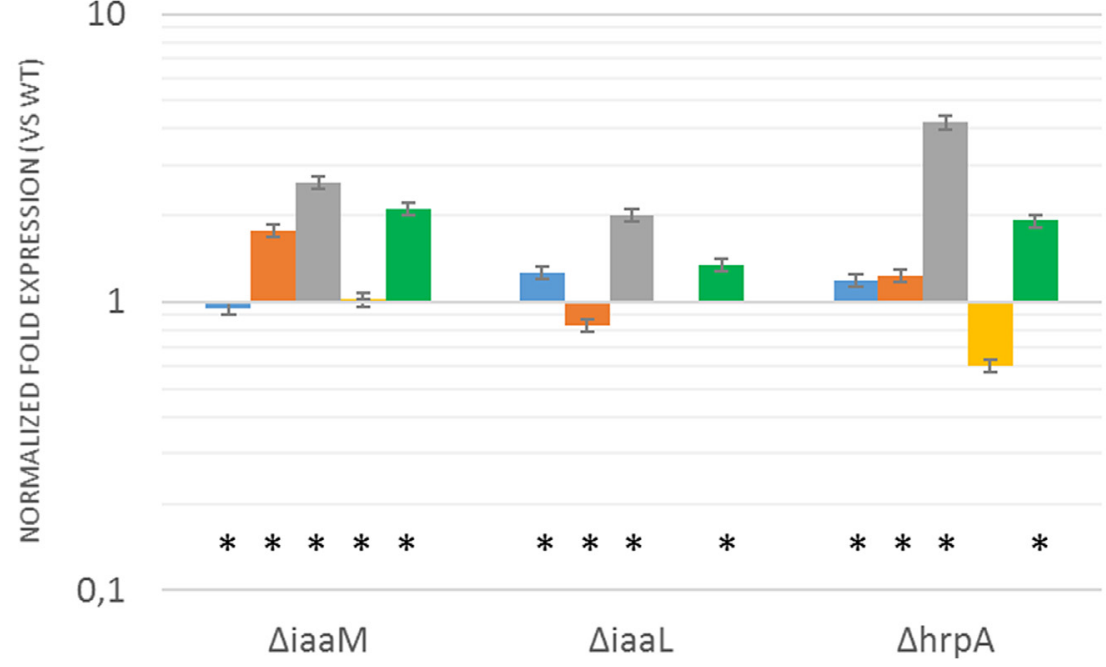

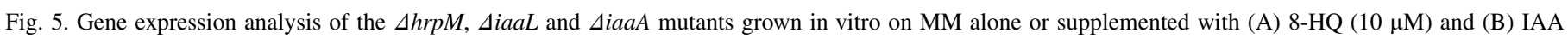

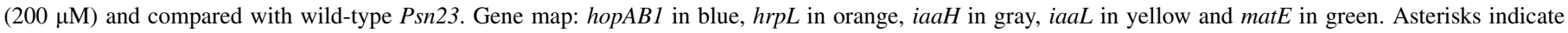
significant differences compared with wild-type $P s n 23$ supplemented with the same treatment at $\mathrm{p}<0.05$.

Antibiotic resistance is among the adverse conditions toward which IAA increases tolerance in $E$. coli, in which indole has been shown to turn on drug efflux pumps $[62,63]$. An analogous relationship between IAA/indole biosynthesis and drug resistance has not been reported to date for phytopathogenic bacteria belonging to the $P$. syringae group, whereas IAA production and its increase during the early phases of infection have been shown to be essential for alterations in host auxin signaling, to enhance plant susceptibility and to promote successful infection [15].

In the present study, IAA metabolism, not just its biosynthesis, was found to be an essential virulence determinant for $P$. savastanoi. In fact, the $\Delta i a a L$ mutant was found to be hypervirulent on its host plant $N$. oleander, where it is able to reach higher in planta population densities and cause more
A

B

extended hyperplastic symptoms than wild-type Psn23. This finding was fully coherent with the increased amounts of free IAA produced by $\triangle i a a L$ in comparison to $P s n 23$, as assessed using the Salkowski assay and HPLC MS. Conversely and as expected, the $\triangle i a a M$ mutant was found to be hypovirulent. This $\Delta$ iaaL phenotype contrasted with data reported thus far for $P$. savastanoi and $P$. syringae pv. tomato $\mathrm{DC} 3000$ $[30,64,65]$. However, opposite results for $P$. savastanoi could likely be due to downstream transcriptional consequences derived from inactivation of the $i a a L$ gene by transposon mutagenesis [30]. Concerning P. syringae pv. tomato DC3000, previous reports are conflicting, mainly due to substantial differences in the experimental design of the pathogenicity tests applied [64,65]. Moreover, it is reasonable that IAA metabolism has different mechanisms in $P$. syringae pv. 
tomato DC3000 compared with those adopted by a hyperplastic bacterium such as $P s n 23$.

According to data from phenotypic characterization caused by PM technology, both $\triangle i a a L$ and $\Delta i a a M$ mutants were shown to be more sensitive than the wild type Psn 23 towards some antibiotics and biocides, with significantly reduced resistance to $8-\mathrm{HQ}$. This quinoline derivative is produced by plants in nature, generally secreted into their exudates and used as an antimicrobial agent in agriculture and other industrial sectors during chemical synthesis. Several mechanisms have been proposed to support 8-HQ antibiotic-like activity, such as a lipophilic chelator and an inhibitor of TTSS, of multi-drug efflux pumps and of ribonucleic acid synthesis, although definitive evidence is not yet available [66,67]. Overall, PM data concerning the sensitivity of both $\triangle i a a L$ and $\triangle i a a M$ to 8 -HQ was also confirmed for $P$. savastanoi pv. nerii, as already known for $E$. coli. Thus, IAA has a supplementary role as a fitness cost for survival of these bacteria under stressful conditions, such as the presence of antimicrobials produced by the antagonists they find in their epiphytic phase and by the host plant during infection. Similarly, most $P$. syringae pathovars produce IAA even in the absence of hyperplastics and the $i a a L$ gene is widespread in $P$. syringae sensu lato. This finding strongly supports the existence of additional roles for IAA besides its involvement in plantbacterial phytopathogen interactions, to manipulate plant auxin signaling and even to enhance resistance to antimicrobial and toxic compounds.

Here we demonstrate that the $\triangle h r p A$ mutant, with an impaired TTSS and diminished pathogenicity, is also more sensitive than its wild type Psn 23 towards 8 -HQ. The existence of a physiological link between IAA metabolism and TTSS is already known. In particular, high IAA concentrations (up to $1 \mathrm{mM}$ ) have been found to have a strong inhibitory effect on the TTSS functionality of $P$. savastanoi pv. savastanoi [29] and further demonstrated herein for P. savastanoi pv. nerii Psn 23. According to this inhibitory activity of IAA on TTSS, the bacterial content of this auxin in its biologically active form must be carefully regulated and modulated in different manners during the various phases of the interaction of phytopathogenic bacteria with their host plants, to guarantee their epiphytic and endophytic survival as well as successful infection. The tight control of intracellular levels of free IAA, and therefore of IAA metabolism, must be even more stringent for a hyperplastic phytopathogenic bacterium such as $P$. savastanoi, in which the amount of free IAA is pivotal for development of typical symptoms.

In silico analysis of the Psn 23 genomic region, including the iaaM/iaaH operon and the iaaL gene, further supports this functional connection between IAA metabolism and TTSS, according to the presence of $h r p$ box motifs in their promoters. Moreover, this analysis introduces an additional element to relate these systems that could explain the higher sensitivity to 8-HQ observed in the PM experiments for the AiaaL, DiaaM and $\Delta h r p A$ mutants in comparison to wild-type Psn23. Close to $i a a L$, a gene encoding a putative MATE was found, as also recently reported for $P$. syringae pv. tomato DC3000 and $P$. savastanoi pv. savastanoi NCPPB3335, and it was highly conserved among $P$. syringae bacteria belonging to genome species $3[64,68]$. In the promoter region upstream of the matE gene of Psn23, an $h r p$ box sequence was found, suggesting its HrpL-dependent transcription.

In addition, several other features were identified which could be considered to simultaneously regulate intracellular IAA levels and TTSS activation and differentially regulate them during the course of bacterial infection. Here, for the first time, a sequence resembling the AuxRE of IAA-inducible plant promoters was identified in $P$. savastanoi, located at the $5^{\prime}$ end of the iaaM/iaaH operon, as well as at that of the iaaL gene. To date, a similar prokaryotic auxin-responsive element has been reported and found to be active only in the plant growth-promoting rhizobacterium A. brasilense, in which the ipdC gene is activated by IAA, the end-product of this pathway, via positive feedback regulation [48]. The AuxRE elements identified herein in Psn 23 are preceded by a conserved $h r p$ box motif. This modular architecture resembles that of plant composite AuxREs, in which the TGTCTC element is not sufficient to confer auxin responsiveness to the promoters [69]. In composite AuxREs, the TGTCTC element requires a coupling element that is located close to or overlapping the TGTCTC motif, which confers constitutive expression of the promoter to which it belongs and is not responsive to auxin. Thus, the TGTCTC element acts as a repressor of expression induced by the constitutive element when auxin levels are low. Conversely, this repression is released in response to high auxin levels and the expression driven by the composite AuxREs is activated. Basically, we hypothesize that, in P. savastanoi, IAA synthesis and conjugation are regulated by IAA. The DS element associated with the AuxRE of iaaL, but not with that of the iaaM/iaaH operon, would allow differential IAA-inducible expression of these genes in $P$. savastanoi, as expected based on their function in IAA metabolism. In particular, at high IAA concentrations, the DS element of iaaL would guarantee its IAA inducibility by releasing the repression caused by TTSS through HrpL or other unknown TTSS-dependent transcription factors, as observed for the ipdC gene of $A$. brasilense. A similar scenario would explain the production of IAA by $P$. savastanoi after successful infection, which is essential to support the development of hyperplastic knots in which the bacterium resides and thus avoid necrosis of the infected plant tissues. Accordingly, IAA-producing strains of $P$. agglomerans, which are sometimes associated with $P$. savastanoi in hyperplastic knots on olives, have been shown to determine an increase in the size of these knots unless their population is larger than that of $P$. savastanoi (1:100 ratio) at the beginning of the infection process [70]. The inactivation of TTSS expression and functionality after this system has served its purpose is a conserved phenomenon that occurs in other Gram-negative pathogens following successful infection of their hosts [71-73]. The putative MATE transporter encoded by matE would further contribute to this picture by mediating IAA efflux, as well as playing a likely role in drug resistance (Fig. 6). This hypothesis is further supported by the higher expression levels of 


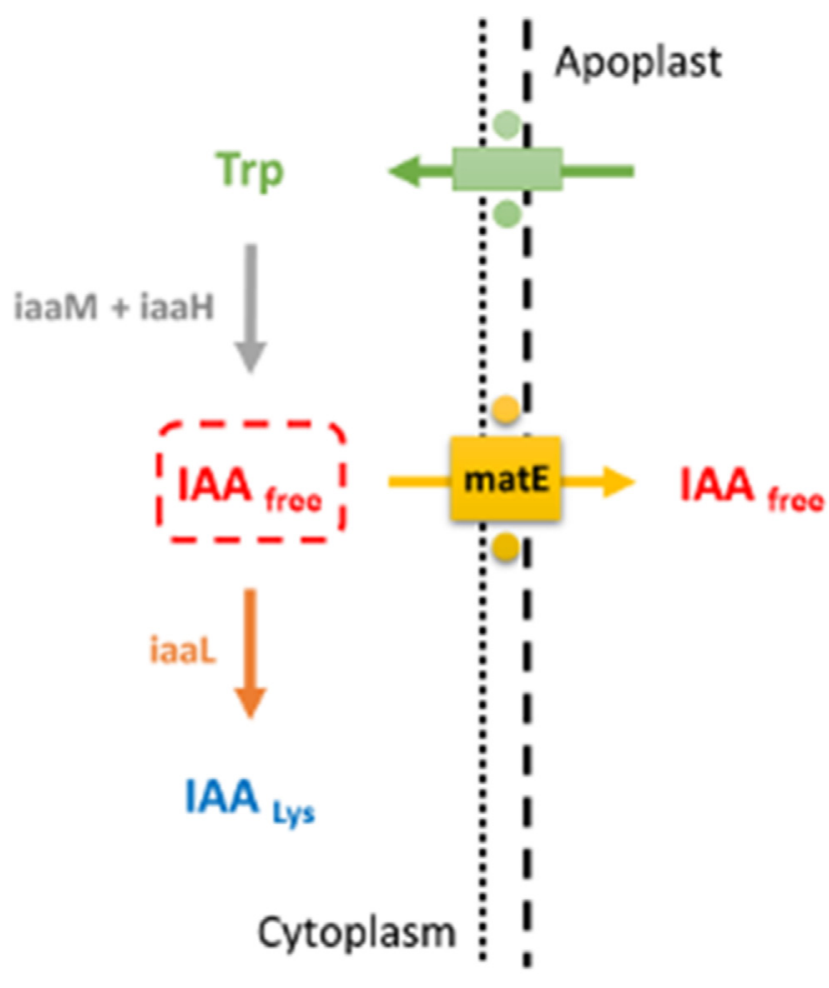

Fig. 6. Proposed model for integrated IAA biosynthesis, conjugation and transport in P. savastanoi pv. nerii strain Psn23.

matE in the three mutants examined herein in the presence of IAA, to simulate specific stages of the infection process when TTSS is downregulated or even switched off. The hypothetical MATE transporter is encoded to mediate IAA efflux. Very recently, the MATE transporter Mte1 of the ectomycorrhizal fungus Tricholoma vaccinum was shown to export IAA during its compatible interaction with the host, positively regulating ectomycorrhiza formation and morphology [52]. Interestingly, some multidrug resistance-like genes of Arabidopsis have also been shown to transport IAA [14]. In P. savastanoi, the hypothetical MATE-mediated transport of IAA occurs at a reduced rate when TTSS is switched on by activation of its hrp box, and thus IAA levels are low, presumably during the initial steps of infection. Conversely, as the intracellular IAA levels increase, mat $E$ is further upregulated following transcriptional activation of the downstream gene iaaL, as occurs for genes that are part of the same operon. In fact, the pivotal importance of operons in the regulation of bacterial gene networks has been recently demonstrated in $E$. coli, in which the expression of a gene that is part of an operon increases with the length of the operon and according to its distance from the end of the operon during its transcription. By increasing the so-called "transcription distance", there is more time for translation to occur during transcription, which will increase expression of genes in the operon proportionally to their transcription distances [74]. To confirm this scenario, in P. syringae pv. tomato DC3000, the matE and iaaL genes were demonstrated to be transcribed both dependently and independently [64].

To the best of our knowledge, PM technology was applied herein for the first time to $P$. savastanoi and also used in the $P$. syringae group to assess chemical sensitivity patterns. Until now, PM has been used to screen the protein-ligand interactions of $P$. syringae pv. actinidiae chemoreceptors [75] and a modified phenoarray approach was applied to analyze the apoplast-adapted nutrient assimilation pathways of $P$. syringae pv. tomato DC3000 [76]. Although it has not been definitely confirmed that the 8-HQ efflux in Psn23 is mediated directly by the transporter encoded by the matE gene, the PM technology approach used herein demonstrated that the impact caused by TTTS and IAA metabolism on the $P$. savastanoi fitness goes beyond its pathogenicity and virulence and also involves drug and antimicrobial resistance. Moreover, it is reasonable to hypothesize that the same phenomenon also occurs in non-gall-forming phytopathogenic and plantassociated bacteria that are able to synthesize and conjugate IAA. Despite not being the main aim of this study, other relevant and encouraging data were also found that warrant future investigations, such as the higher sensitivity of the $\triangle i a a M$ mutant to oxytetracycline and the higher resistance of the $\triangle h r p A$ mutant to hydroxylamine, sodium azide and polymixin $\mathrm{B}$, in comparison to the wild-type $P \operatorname{sn} 23$. In conclusion, taken together, these findings provide information for the development of alternative strategies to control pathogenic bacteria through the use of natural products containing indolebased molecules [77].

\section{Authors' contributions}

MC, CB, LG, CV and ST conceived and designed the research and experiments, and assessed and interpreted the results. MC, CB, FD, MVO and SM carried out bioinformatic analysis, mutagenesis experiments, pathogenicity trials and expression analysis. FD, LG and CV carried out PM analysis. $\mathrm{BC}, \mathrm{MO}$ and EB carried out experiments on IAA and IAA-Lys identification and quantitative detection. MC, CB, FD, CV and ST wrote the paper.

All authors read and approved the final manuscript.

\section{Conflict of interest}

The authors declare that they have no competing interests. This paper does not contain any studies carried out on human or animal subjects.

\section{Acknowledgements}

We gratefully acknowledge the EU commission (project LIFE12 ENV/IT/000336 AFTER $\mathrm{Cu}$ and project LIFE13 ENV/IT/000461 EVERGREEN) and the Ente Cassa di Risparmio di Firenze (project $n^{\circ}$ 2014/0724) for financially supporting this study.

\section{Appendix A. Supplementary data}

Supplementary data related to this article can be found at http://dx.doi.org/10.1016/j.resmic.2016.09.002. 


\section{References}

[1] Santner A, Estelle M. Recent advances and emerging trends in plant hormone signaling. Nature 2009;459:1071-8.

[2] Kieffer M, Neve J, Kepinski S. Defining auxin response contexts in plant development. Curr Opin Plant Biol 2010;13:12-20.

[3] Ljung K. Auxin metabolism and homeostasis during plant development. Development 2013;140:943-50.

[4] Normanly J, Cohen JD, Fink GR. Arabidopsis thaliana auxotrophs reveal a tryptophan-independent biosynthetic pathway for indole-3-acetic acid. Proc Natl Acad Sci U S A 1993;90:10355-9.

[5] Wright AD, Sampson MB, Neuffer MG, Michalczuk L, Slovin JP, Cohen JD. Indole-3-acetic acid biosynthesis in the mutant maize orange pericarp, a tryptophan auxotroph. Science 1991;254:998-1000.

[6] Wang B, Chu J, Yu T, Xu Q, Sun X, Yuan J, et al. Tryptophan-independent auxin biosynthesis contributes to early embryogenesis in Arabidopsis. Proc Natl Acad Sci U S A 2015;112:4821-6.

[7] Nonhebel HM. Tryptophan-independent indole-3-acetic acid synthesis: critical evaluation of the evidence. Plant Physiol 2015;169:1001-5.

[8] Ludwig-Müller J. Auxin conjugates: their role for plant development and in the evolution of land plant. J Exp Bot 2011;62:1757-73.

[9] Woodward AW, Bartel B. Auxin: regulation, action and interaction. Ann Bot 2005;95:707-35.

[10] Dharmasiri N, Dharmasiri S, Weijers D, Lechner E, Yamada M, Hobbie L, et al. Plant development is regulated by a family of auxin receptor F box proteins. Dev Cell 2005;9:109-19.

[11] Vande Broek A, Lambrecht M, Eggermont K, Vanderleyden J. Auxins upregulate expression of the indole-3-pyruvate decarboxylase gene in Azospirillum brasilense. J Bacteriol 1999;181:1338-42.

[12] Hagen G, Guilfoyle T. Auxin-responsive gene expression: genes, promoters and regulatory factors. Plant Mol Biol 2002;49:373-85.

[13] Zazímalová E, Krecek P, Skůpa P, Hoyerová K, Petrásek J. Polar transport of the plant hormone auxin - the role of PIN-FORMED (PIN) proteins. Cell Mol Life Sci 2007;64:1621-37.

[14] Noh B, Murphy AS, Spalding EP. Multidrug resistance-like genes of Arabidopsis required for auxin transport and auxin-mediated development. Plant Cell 2001;13:2441-54.

[15] Ludwig-Müller J. Bacteria and fungi controlling plant growth by manipulating auxin: balance between development and defense. J Plant Physiol 2015;172:4-12.

[16] Navarro L, Dunoyer P, Jay F, Arnold B, Dharmasiri N, Estelle M, et al. A plant miRNA contributes to antibacterial resistance by repressing auxin signaling. Science 2006;312:436-43.

[17] Chang X, Riemann M, Liu Q, Nick P. Actin as deathly switch? How auxin can suppress cell-death related defence. PLoS ONE 2015;10: e0125498.

[18] Spoel SH, Dong X. Making sense of hormone cross-talk during plant immune responses. Cell Host Microbe 2008;3:348-51.

[19] Fu J, Wang S. Insights into auxin signaling in plant-pathogen interactions. Front Plant Sci 2011;2:74.

[20] Glickmann E, Gardan L, Jacquet S, Hussain S, Elasri M, Petit A, et al. Auxin production is a common feature of most pathovars of Pseudomonas syringae. Mol Plant Microbe Interact 1998;11:156-62.

[21] Surico G, Iacobellis NS, Sisto A. Studies on the role of indole-3-acetic acid and cytokinins in the formation of knots on olive and oleander plants by Pseudomonas syringae pv. savastanoi. Physiol Plant Pathol 1985;26:309-20.

[22] Patten CL, Blakney AJ, Coulson TJ. Activity, distribution and function of indole-3-acetic acid biosynthetic pathways in bacteria. Crit Rev Microbiol 2013:39:395-415.

[23] González-Lamothe R, El Oirdi M, Brisson N, Bouarab K. The conjugated auxin indole-3-acetic acid-aspartic acid promotes plant disease development. Plant Cell 2012;24:762-77.

[24] Cui F, Wu S, Sun W, Coaker G, Kunkel B, He P, et al. The Pseudomonas syringae type III effector AvrRpt2 promotes pathogen virulence via stimulating Arabidopsis auxin/indole acetic acid protein turnover. Plant Physiol 2013;162:1018-29.
[25] Nomura K, Debroy S, Lee YH, Pumplin N, Jones J, He SY. A bacterial virulence protein suppresses host innate immunity to cause plant disease. Science 2006;313:220-3.

[26] Zhao Y. Auxin biosynthesis and its role on plant development. Annu Rey Plant Biol 2010;61:49-64.

[27] Barash I, Manulis-Sasson S. Virulence mechanisms and host specificity of gall-forming Pantoea agglomerans. Trends Microbiol 2007;15: $538-45$.

[28] Sisto A, Cipriani MG, Morea M. Knot formation caused by Pseudomonas syringae subsp. savastanoi on olive plants is Hrp-dependent. Phytopatol 2004;94:484-9.

[29] Aragon I, Perez-Martinez I, Moreno-Perez A, Cerezo M, Ramos C. New insights into the role of indole-3-acetic acid in the virulence of Pseudomonas savastanoi pv. savastanoi. FEMS Microbiol Lett 2014;356: 184-92.

[30] Glass NL, Kosuge T. Cloning of the gene for indoleacetic acid-lysine synthetase from Pseudomonas syringae subsp. savastanoi. J Bacteriol 1986;166:598-603.

[31] Tiryaki I, Staswick PE. An Arabidopsis mutant defective in jasmonate response is allelic to the auxin-signaling mutant axr1. Plant Physiol 2002; 130:887-94.

[32] King EO, Ward MK, Raney DE. Two simple media for the determination of pyocianine and fluorescein. J Lab Clin Med 1954;44:301-7.

[33] Huynh TV, Dahlbeck D, Staskawicz BJ. Bacterial blight of soybean: regulation of a pathogen gene determining host cultivar specificity. Science 1989;245:1374-7.

[34] Miller H. Experiments in molecular genetics. Cold Spring Harbor, N.Y. Cold Spring Harbor Laboratory; 1972.

[35] Sisto A, Cipriani M, Tegli S, Cerboneschi M, Stea G, Santilli E. Genetic characterization by fluorescent AFLP of Pseudomonas savastanoi pv. savastanoi strains isolated from different host species. Plant Pathol 2007 $56: 366-72$.

[36] Tegli S, Cerboneschi M, Marsili Libelli I, Santilli E. Development of a versatile tool for the simultaneous differential detection of Pseudomonas savastanoi pathovars by End Point and Real-Time PCR. BMC Microbiol 2010;10:156.

[37] Sambrook J, Fritsch EF, Maniatis TA. Molecular cloning: a laboratory manual. 2nd ed. New York, NY, USA: Cold Spring Harbor Laboratory Press; 1989.

[38] Thompson JD, Higgins DG, Gibson TJ. CLUSTALW: improving the sensitivity of progressive multiple sequence alignment through sequence weighting, position-specific gap penalties and weight matrix choice. Nucleic Acids Res 1994;22:4673-80.

[39] Altschul SF, Gish W, Miller W, Myers EW, Lipman DJ. Basic local alignment search tool. J Mol Biol 1990;215:403-10.

[40] Yang CH, Gavilanes-Ruiz M, Okinaka Y, Vedel R, Berthuy I, Boccara M, et al. hrp genes of Erwinia chrysanthemi 3937 are important virulence factors. Mol Plant Microbe Interact 2002;15:472-80.

[41] Pérez-Martínez I, Rodríguez-Moreno L, Lambertsen L, Matas MI, Murillo J, Tegli S, et al. Fate of a Pseudomonas savastanoi pv. savastanoi type III secretion system mutant in olive plants (Olea europaea L.). Appl Environ Microbiol 2010;76:3611-9.

[42] Ehmann A. The Van Urk-Salkowski reagent - a sensitive and specific chromogenic reagent for silica gel thin-layer chromatographic detection and identification of indole derivatives. J Chromatogr 1977;132:267-76.

[43] Qin G, Gu H, Zhao Y, Ma Z, Shi G, Yang Y, et al. An indole-3-acetic acid carboxyl methyltransferase regulates Arabidopsis leaf development. Plant Cell 2005;17:2693-704.

[44] Murashige T, SKOOG F. A revised medium for rapid growth and bioassays with tobacco tissue cultures. Physiol Plant 1962;15:473-97.

[45] Gori A, Cerboneschi M, Tegli S. High-resolution melting analysis as a powerful tool to discriminate and genotype Pseudomonas savastanoi pathovars and strains. PLoS ONE 2012;7:e30199.

[46] Baker CJ, Atkinson MM, Collmer A. Concurrent loss in Tn5 mutants of Pseudomonas syringae pv. syringae of the ability to induce the hypersensitive response and host plasma membrane $\mathrm{K}+/ \mathrm{H}^{+}$exchange in tobacco. Phytopathology 1987;77:1268-72. 
[47] Bochner BR, Gadzinski P, Panomitros E. Phenotype Microarrays for high-throughput phenotypic testing and assay of gene function. Genome Res 2001;11:1246-55.

[48] Lambrecht M, Vande Broek A, Dosselaere F, Vanderleyden J. The ipdC promoter auxin-responsive element of Azospirillum brasilense, a prokaryotic ancestral form of the plant AuxRE? Mol Microbiol 1999;32: 889-91.

[49] Pandey R, Swamy KV, Khetmalas MB. Indole: a novel signaling molecule and its applications. Indian J Biotechnol 2013;12:297-310.

[50] Spaepen S, Vanderleyden J. Auxin and plant-microbe interactions. Cold Spring Harb Perspect Biol 2011;3:a001438.

[51] Mills LJ, Van Staden J. Extraction of cytokinins from maize, smut tumors of maize and Ustilago maydis cultures. Physiol Plant Pathol 1978;13: 73-80.

[52] Krause K, Henke C, Asiimwe T, Ulbricht A, Klemmer S, Schachtschabel S, et al. Biosynthesis and secretion of indole-3-acetic acid and its morphological effects on Tricholoma vaccinum-spruce ectomycorrhiza. Appl Environ Microbiol 2015;81:7003-11.

[53] Maor R, Haskin S, Levi-Kedmi H, Sharon A. In planta production of indole-3-acetic acid by Colletotrichum gloeosporioides f. sp. Aeschynomene. Appl Environ Microbiol 2004;70:1852-4.

[54] Tsavkelova E, Oeser B, Oren-Young L, Israeli M, Sasson Y, Tudzynski B, et al. Identification and functional characterization of indole-3-acetamide-mediated IAA biosynthesis in plant-associated Fusarium species. Fungal Genet Biol 2012;49:48-57.

[55] Bommarius B, Anyanful A, Izrayelit Y, Bhatt S, Cartwright E, Wang W, et al. A family of indoles regulate virulence and Shiga toxin production in pathogenic E. coli. PLoS ONE 2013;8:e54456.

[56] Lee J, Bansal T, Jayaraman A, Bentley WE, Wood TK. Enterohemorrhagic Escherichia coli biofilms are inhibited by 7-hydroxyindole and stimulated by isatin. Appl Environ Microbiol 2007;73:4100-9.

[57] Yang S, Zhang Q, Guo J, Charkowski AO, Glick BR, Ibekwe AM, et al. Global effect of indole-3-acetic acid biosynthesis on multiple virulence factors of Erwinia chrysanthemi 3937. Appl Environ Microbiol 2007;73: 1079-88.

[58] Liu P, Nester EW. Indoleacetic acid, a product of transferred DNA, inhibits vir gene expression and growth of Agrobacterium tumefaciens C58. Proc Natl Acad Sci U S A 2006;103:4658-62.

[59] Yuan ZC, Liu P, Saenkham P, Kerr K, Nester EW. Transcriptome profiling and functional analysis of Agrobacterium tumefaciens reveals a general conserved response to acidic conditions ( $\mathrm{pH}$ 5.5) and a complex acid-mediated signaling involved in Agrobacterium-plant interactions. J Bacteriol 2008;190:494-507.

[60] Malhotra M, Srivastava S. Organization of the $i p d C$ region regulates IAA levels in different Azospirillum brasilense strains: molecular and functional analysis of ipdC in strain SM. Environ Microbiol 2008;10: 1365-73.

[61] Prusty R, Grisafi P, Fink GR. The plant hormone indoleacetic acid induces invasive growth in Saccharomyces cerevisiae. Proc Natl Acad Sci U S A 2004;101:4153-7.

[62] Bianco C, Imperlini E, Calogero R, Senatore B, Amoresano A, Carpentieri A, et al. Indole-3-acetic acid improves Escherichia coli's defences to stress. Arch Microbiol 2006;185:373-82.
[63] Lee HH, Molla MN, Cantor CR, Collins JJ. Bacterial charity work leads to population-wide resistance. Nature 2010;467:82-5.

[64] Castillo-Lizardo MG, Aragón IM, Carvajal V, Matas IM, PérezBueno ML, Gallegos MT, et al. Contribution of the non-effector members of the HrpL regulon, iaaL and matE, to the virulence of Pseudomonas syringae pv. tomato DC3000 in tomato plants. BMC Microbiol 2015; $15: 165$.

[65] Lam HN, Chakravarthy S, Wei HL, BuiNguyen HC, Stodghill PV, Collmer A, et al. Global Analysis of the HrpL regulon in the plant pathogen Pseudomonas syringae pv. tomato DC3000 reveals new regulon members with diverse functions. PLoS ONE 2014;9:e106115.

[66] Fraser RS, Creanor J. The mechanism of inhibition of ribonucleic acid synthesis by 8 -hydroxyquinoline and the antibiotic lomofungin. Biochem J 1975; 147:401-10.

[67] Prachayasittikul V, Prachayasittikul S, Ruchirawat S, Prachayasittikul V. 8-Hydroxyquinolines: a review of their metal chelating properties and medicinal applications. Drug Des Dev Ther 2013;7:1157-78.

[68] Rodríguez-Palenzuela P, Matas IM, Murillo J, López-Solanilla E, Bardaji L, Pérez-Martínez I, et al. Annotation and overview of the Pseudomonas savastanoi pv. savastanoi NCPPB 3335 draft genome reveals the virulence gene complement of a tumour-inducing pathogen of woody hosts. Environ Microbiol 2010;12:1604-20.

[69] Ulmasov T, Murfett J, Hagen G, Guilfoyle TJ. Aux/IAA proteins repress expression of reporter genes containing natural and highly active synthetic auxin response elements. Plant Cell 1997;9:1963-71.

[70] Marchi G, Sisto A, Cimmino A, Andolfi A, Cipriani MG, Evidente A, et al. Interaction between Pseudomonas savastanoi pv. savastanoi and Pantoea agglomerans in olive knots. Plant Pathol 2006;55:614-24.

[71] Lucchini S, Liu H, Jin Q, Hinton JC, Yu J. Transcriptional adaptation of Shigella flexneri during infection of macrophages and epithelial cells: insights into the strategies of a cytosolic bacterial pathogen. Infect Immun 2005;73:88-102.

[72] Dahan S, Knutton S, Shaw RK, Crepin VF, Dougan G, Frankel G. Transcriptome of enterohemorrhagic Escherichia coli O157 adhering to eukaryotic plasma membranes. Infect Immun 2004;72:5452-9.

[73] Shen DK, Filopon D, Chaker H, Boullanger S, Derouazi M, Polack B, et al. High-cell-density regulation of the Pseudomonas aeruginosa type III secretion system: implications for tryptophan catabolites. Microbiology 2008;154:2195-208.

[74] Lim HN, Lee Y, Hussein R. Fundamental relationship between operon organization and gene expression. Proc Natl Acad Sci U S A 2011;108: 10626-31.

[75] McKellar JLO, Minnell JJ, Gerth ML. A high-throughput screen for ligand binding reveals the specificities of three amino acid chemoreceptors from Pseudomonas syringae pv. actinidiae. Mol Microbiol 2015; 96:694-707.

[76] Rico A, Preston GM. Pseudomonas syringae pv. tomato DC3000 uses constitutive and apoplast-induced nutrient assimilation pathways to catabolize nutrients that are abundant in the tomato apoplast. Mol Plant Microbe Interact 2008;21:269-82.

[77] Melander RJ, Minvielle MJ, Melander C. Controlling bacterial behavior with indole-containing natural products and derivatives. Tetrahedron 2014;70:6363-72. 